\title{
The influence of type of cement on the degradation of microstructure and transport properties of cement mortars exposed to frost induced damage
}

\author{
Alicja Wieczorek ${ }^{*}$, and Marcin Koniorczyk \\ ${ }^{1}$ Department of Building Physics and Building Materials, Lodz University of Technology, 90-924 \\ Lodz, Al. Politechniki 6, Poland
}

\begin{abstract}
The purpose of the study is to understand how the cyclic water freezing $(0,25,50,75,100$ and 150 freeze-thaw cycles) impacts microstructure and transport properties of cement-based materials. Tests were conducted on cement mortars with different water/cement ratios $(\mathrm{w} / \mathrm{c}=0.45$ and 0.40$)$ and on two types of cement (CEM I and CEM III) without air-entraining admixtures. The changes of pore size distribution and open porosity were investigated by means of mercury intrusion porosimetry. Additionally, the relationship between intrinsic permeability and the water absorption coefficient of cement mortar samples was analysed. The water absorption coefficient and gas permeability were determined using capillary absorption test and the modified RILEMCembureau method. The evolution of transport coefficients with growing number of freeze-thaw cycles were determined on the same sample. It was also established that change of pore structure (a decrease of small pore volume $<100 \mathrm{~nm}$ and increase of larger pores $>100 \mathrm{~nm}$ ) induces an increase of water transport parameters such as permeability and water absorption coefficient. The higher gas permeability corresponds to the higher internal damage. In particular, it is associated with the change of cement mortar microstructure, which indicates damage of narrow channels in the pore structure of cement mortars.
\end{abstract}

\section{Introduction}

A complex pore microstructure is characteristic for the cement-based materials. The total porosity consists of the closed pores, which do not contribute significantly to the permeability of the material, and open pores. The pore network consists of capillaries, which are interconnected in a disordered way through a system of smaller pores. The size of the pores varies from nanometres (gel pores) to millimetres (air voids) [1]. The evolution of transport properties of cement-based materials due to the environmental loading is essential for a profound understanding of damage phenomena. The transport properties, depend mainly on the hydrated cement paste structure, including size, distribution, shape,

\footnotetext{
${ }^{*}$ Corresponding author: alicja.marciniak@p.lodz.pl
} 
tortuosity and continuity of pores. Therefore, the relationship between microstructure, transport properties and durability of cement-based materials is of particular importance when the ice-induced deterioration is considered. Since the parameters characterizing the inner structure of the cement-based materials, such as porosity or permeability, determine not only their strength, but also risk of degradation of cement matrix due to aggressive environment $[2,3]$.

The objective of this study is to examine experimentally the effect of cycling water freezing $(0,25,50,75,100$ and 150 freeze-thaw cycles) on the microstructure and transport properties of cement mortars. The mercury intrusion porosimetry has been used to determine influence of the ice formation on the pore size distributions. The water absorption coefficient and gas permeability are determined using capillary absorption test and the modified RILEM-Cembureau method. The evolution of transport coefficients with growing number of freeze-thaw cycles were determined on the same sample.

\section{Materials and Methods}

The cement mortars' recipe is given in Table 1 . The composites are produced on the basis of CEM I (Z_1 and Z_2) and CEM III (Z_3 and Z_4) cement and natural quartz sand with different $\mathrm{w} / \mathrm{c}$ ratios $(\mathrm{w} / \mathrm{c}=0.45$ and 0.40$)$. The specimens, prepared according to the EN 1961 standard [4], are formed in PVC tubes with diameter $50,5 \mathrm{~mm}$ and height $70 \mathrm{~mm}$. After casting, the samples are cured for 1 day, then demolded and kept in water at $20^{\circ} \mathrm{C}$ for 90 days. After initial conditioning, $10 \mathrm{~mm}$ from upper and bottom sides of each samples of mortars are cut away. Then, the reference samples are preserved in water while other samples are subjected to freeze-thaw cycles. The temperature changes are imposed by the accelerated freeze-thaw climatic chamber, according to PN-88/B-06250 [5].

Table 1. Cement mortars composition.

\begin{tabular}{|c|c|c|c|c|c|}
\hline Series & Cement $[g]$ & Sand $[g]$ & Water $[g]$ & Plasticizer $[\mathrm{g}]$ & $\mathbf{w} / \mathbf{c}[-]$ \\
\hline Z_1 & \multirow{2}{*}{ CEM I 42,5R } & \multirow{4}{*}{2700} & 405 & 4.95 & 0.45 \\
\hline Z_2 & & & 360 & 8.10 & 0.40 \\
\hline Z_3 & \multirow{2}{*}{ CEM III/A 42,5N LH/HSR/NA } & & 405 & 4.05 & 0.45 \\
\hline$Z_{-} 4$ & & & 360 & 8.55 & 0.40 \\
\hline
\end{tabular}

\subsection{Pore size distribution}

Mercury intrusion porosimetry is a method used to characterize the distribution of the pore size in the cement-based materials. It is assumed that the material consists of cylindrical pores, which are directly connected to the source of mercury. A sample is placed in a measuring chamber filled with mercury, which is a non wetting fluid. As pressure is applied on the mercury, it intrudes into the pore system. The higher the pressure is, the smaller pores are filled with the mercury. The diameter of the pores, which are filled at a given pressure, can be calculated according to the Washburn equation [6]:

$$
d=(-4 \gamma \cdot \cos \theta) / \mathrm{P}
$$

where $d$ is the diameter of the cylindrical pore, $\gamma$ the mercury surface tension (assumed as $0.48 \mathrm{~N} / \mathrm{m}$ ), $\theta$ the contact angle of mercury on the solid surface (assumed as $130^{\circ}$ ), and $P$ the 
pressure applied. For the applied pressure, pores of diameter from $6 \mathrm{~nm}$ up to $100 \mu \mathrm{m}$ can be detected.

It has to be emphasized that this method is characterized by some limitations and simplifications, which have to be taken into account during analyzing the results [7]. A complex pore microstructure is characteristic for the cement-based materials. The irregular, not of cylindrical shape pores can cause inaccurate values of the pore diameters [8]. However, this inaccuracy refers to all the samples tested with this method, so a qualitative comparison between samples seems justifiable.

Three cores, cylinders of $10 \mathrm{~mm}$ diameter and $15 \mathrm{~mm}$ length from one sample after each number of freeze-thaw cycles for each mortar series are studied. All the samples are dried at $60{ }^{\circ} \mathrm{C}$ until constant mass is reached. The presented results are the average of three cores tested for each case.

\subsection{Permeability}

The test procedure is similar to that recommended in $[9,10]$. The measurements are taken using an appropriately modified device. Because of the chamber structure, the PVC tube is one of the elements of the gas permeability chamber. Before every test, the tightness is examined by means of gas leak detector spray. The gas permeability test is conducted for four values of inlet pressure, which are picked depending on tightness and destruction level of particular sample. Apparent gas permeability, $k_{a}$, is calculated at a given pressure using following equation [9]:

$$
k_{\mathrm{a}}=\left(2 p_{0} Q_{i} \cdot L \cdot \mu\right) /\left[\mathrm{A} \cdot\left(p_{\mathrm{i}}^{2}-p_{0}^{2}\right)\right]
$$

where $p_{i}$ and $p_{0}$ are the inlet and outlet pressure, $Q_{i}$ is the volumetric flow rate, $L$ is the sample thickness in the direction of the gas flow, $A$ is the area of the sample cross-section, and $\mu$ is the viscosity of oxygen. Before the measurements, steady state flow has to be established. This condition is verified by taking two measurements separated by 10 minute time interval. It is assumed, that if two values differ by less than $3 \%$ the steady state flow condition is achieved. To consider Knudsen flow an intrinsic coefficient of permeability, $k_{v}$, is calculated using Klinkenberg relationship [11]:

$$
k_{\mathrm{a}}=k_{\mathrm{v}} \cdot\left[1+\left(b / p_{m}\right)\right]
$$

where $b$ is the Klinkenberg coefficient and $p_{m}=\left(p_{i}+p_{0}\right) / 2$ is the mean gas pressure. The intrinsic permeability of specimens can be given by a linear regression of the apparent permeabilities to the infinite average pressure.

After the cycling water freezing the cement mortar specimens are prepared for gas permeability test according to steps:

- drying at the temperature $60^{\circ} \mathrm{C}$ for 14 days;

- storing the samples in $20^{\circ} \mathrm{C}$ and $\mathrm{RH}=50 \%$ for 7 days;

- insulating the lateral sides of each sample by means of resin and pasting the samples inside PVC tubes. Moreover, all samples designed for gas permeability test are oven-dried at $60^{\circ} \mathrm{C}$ and subsequently cooled for $24 \mathrm{~h}$ in a desiccators at $20^{\circ} \mathrm{C}$ before being tested.

\subsection{Capillarity test}

After the measurements of the gas permeability are completed, the water absorption coefficient, A $\left[\mathrm{kg} /\left(\mathrm{m}^{2} \cdot \mathrm{s}^{1 / 2}\right)\right]$, according to PN-EN ISO 15148 [12] is studied. The measurements, consist in recording the mass changes of the samples remaining in constant contact with water, are performed after 5 and 20 minutes and after $1,2,3,4,6,8,12,24 \mathrm{~h}$. The 
uncontrolled exchange of moisture through lateral sides with the surrounding is prevented by PVC tube. Water absorption coefficient is mathematically defined as a tangent to capillary water content function and square root of time:

$$
A=\Delta \mathrm{m}_{\mathrm{t}} /(F \cdot \sqrt{ } t)
$$

where $\Delta m_{t}$ is the mass increase of the sample during time $t$ and $F$ is the sample surface area in direct contact with water.

\section{Results}

\subsection{Pore size distribution}

The comparison of the averaged cumulative pore volume, pore size distribution is presented in Fig. 1 and Fig. 2, respectively.

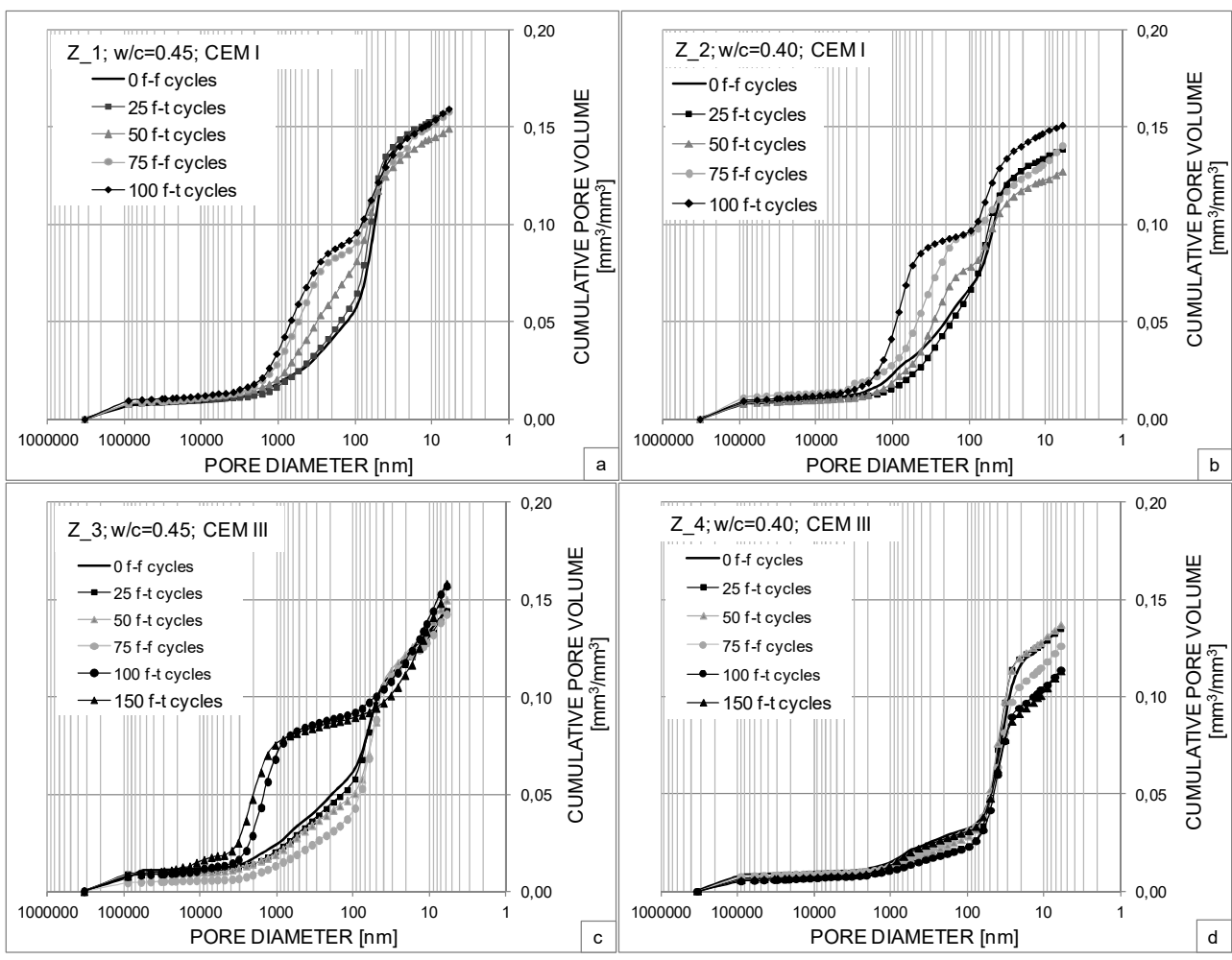

Fig. 1. Comparison of the cumulative pore volume obtained by means of MIP for series $Z \_1$ (a) and Z_2 (b) after 0, 25, 50, 75 and 100 freeze-thaw cycles and for series $Z \_3$ (c) and Z_4 (d) after 0, 25, $50,75,100$ and 150 freeze-thaw cycles.

The differences between total porosities of cement mortar samples after freeze-thaw cycles is small, when compared with the reference samples, Fig. 1. However, according to the MIP test results it is evident that frost damage caused a redistribution of pore sizes, Fig. 2. Similar observations were reported for concrete [13]. Ice induced damage open larger pores and thus crystallization pressure increases. With the increasing number of $\mathrm{f}$-t cycles, the visible destruction of pores can be noticed. Furthermore, after 50th f-t cycles, for 
cement mortar made with CEM I ( $Z \_1$ and $\left.Z \_2\right)$ the differential pore size distribution becomes bimodal, Fig. 2a,b. For example for mortars $Z_{-} 1$, after $50 \mathrm{f}$-t cycles the dominant pore size is shifted from about $50 \mathrm{~nm}$ up to $60 \mathrm{~nm}$. With further increase of f-t cycle number, the second peak rises around $500 \mathrm{~nm}$. In conclusion, a decrease of small pore volume (from $30 \mathrm{~nm}$ up to $100 \mathrm{~nm}$ ) and increase of larger pores (with diameter ranges from $100 \mathrm{~nm}$ to $3 \mu \mathrm{m}$ ) are noticed, Fig. 2 a.

The positive impact of CEM III on ice-induced microstructure degradation is visible. Comparing the value of the threshold diameter, below which there is a rapid mercury intrusion and above which there is a little intrusion, one can notice, that this value is smaller than the value obtained for specimens made with CEM I. In the case of mortars made with CEM III the cement matrix is more compacted and less porous. In addition, these mortars feature lower gas permeability. In contrast, for reference specimens made with CEM I, the permeability increases about four times.

However, for a high $\mathrm{w} / \mathrm{c}$ ratio, the application of CEM III does not eliminate frost damaged. The ice-induced damage of microstructure of series $Z \_3$ is consequently reduce until 75 freeze-thaw cycles. For $Z \_3$ mortars, significant changes in pore size distribution can be noticed between 75 and 100 freeze-thaw cycles. The samples made of $Z_{-} 4$ mortar are more resistant to cyclic water freezing, no structure deterioration can be noticed until 150 frost cycle.

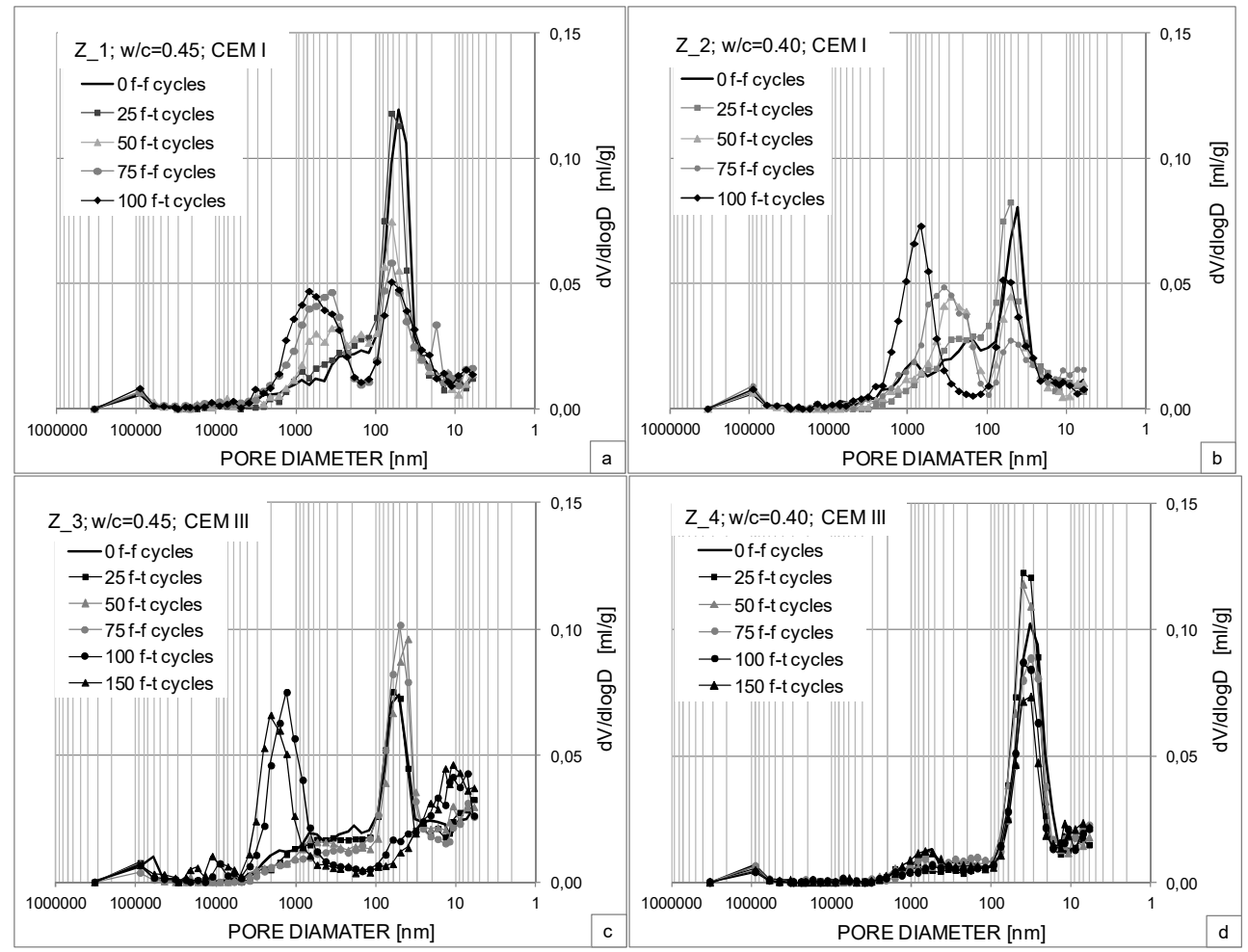

Fig. 2. Comparison of the pore size distribution obtained by means of the MIP after freeze-thaw cycles for: a) Z_1, b) Z_2, c) Z_3 and d) $Z \_4$.

\subsection{Transport properties}

The relation between intrinsic permeability and number of freeze and thaw cycles for all analyzed cement mortars is presented in Table 2 . The coefficient of variation, $c_{v}$, defined as 
a ratio of the standard deviation and the mean value of permeability is also shown in Table 2. The permeability of samples which are subjected to $n$ freeze-thaw cycles is denoted as $k_{v n}$. The presented value is an average value of three specimens of series $Z \_1$ and $Z \_3$ and four samples of series $Z \_2$ and $Z \_4$ for each number of freeze-thaw cycles. The number of specimens for $Z \_3$ after $\overline{1} 00$ and $\overline{1} 50 \mathrm{f}$-t cycles is increased to five, because of a large value of coefficient of variation, $c_{v}$, see Table 2 .

Based on the obtained results one can noticed that the type of cement has a significant impact on the permeability coefficient of cement mortars exposed to cyclic freezing, Table 2. It is established that gas permeability increases with the rising number of $\mathrm{f}-\mathrm{t}$ cycles. The permeability increases exponentially with the number of $f-t$ cycles for mortars $Z \_1$ and Z_2. After $100 \mathrm{f}-\mathrm{t}$ cycles, the average intrinsic coefficient of permeability increase from $4 \times 10^{-18} \mathrm{~m}^{2}$ and $3 \times 10^{-18} \mathrm{~m}^{2}$ to $427 \times 10^{-18} \mathrm{~m}^{2}$ and $317 \times 10^{-18} \mathrm{~m}^{2}$ for $\mathrm{Z} \_1$ and $\mathrm{Z} 22$ mortars, respectively. Based on the obtained results, the internal frost damage of $\bar{Z} 1$ is more extensive than of $Z \_2$ which is caused by higher value of water to cement ratio.

For Z_3 mortars, significant increase of intrinsic coefficient of permeability can be observed between 75 and 100 freeze-thaw cycles. The permeability after the 100th cycle is 450 times higher than the initial permeability and at the end of the 150 th cycle is 3300 times higher, what is in agreement with other research studied this problem, i.e. [14]. According to Wardeh at. el. [14] the sensitivity can be explained by the fact that small pores have a great influence on the permeability and that these are the pores where the porous pressure is related to ice formation.

Table 2. Intrinsic coefficient of permeability after $n$ freeze-thaw cycles, $k_{v n}$-the permeability of the samples which are subjected to $0,25,50,75,100$ and $150 \mathrm{f}$-t cycles, $c_{v}$ - coefficient of variation (ratio of the standard deviation and the mean value of permeability).

\begin{tabular}{|c|c|c|c|c|c|c|}
\hline \multicolumn{7}{|c|}{$k_{v n} \times 10^{-18}\left[\mathrm{~m}^{2}\right] \pm c_{v}[\%]$} \\
\hline$n$ & 0 & 25 & 50 & 75 & 100 & 150 \\
\hline $\begin{array}{c}\mathrm{Z} 1 \\
{[\mathrm{w} / \mathrm{c}=0.4 \overline{5}, \mathrm{CEM} \mathrm{I}]}\end{array}$ & $\begin{array}{c}4.1 \\
( \pm 8 \%)\end{array}$ & $\begin{array}{c}5.1 \\
( \pm 13 \%)\end{array}$ & $\begin{array}{c}16.2 \\
( \pm 15 \%)\end{array}$ & $\begin{array}{c}182.5 \\
( \pm 92 \%)\end{array}$ & $\begin{array}{l}427.0 \\
( \pm 72 \%)\end{array}$ & - \\
\hline $\begin{array}{c}\mathrm{Z} 2 \\
{[\mathrm{w} / \mathrm{c}=0.40, \mathrm{CEM} \mathrm{I}]}\end{array}$ & $\begin{array}{c}3.1 \\
( \pm 18 \%)\end{array}$ & $\begin{array}{c}7.9 \\
( \pm 16 \%)\end{array}$ & $\begin{array}{c}27.7 \\
( \pm 10 \%)\end{array}$ & $\begin{array}{c}58.0 \\
( \pm 9 \%)\end{array}$ & $\begin{array}{c}317.1 \\
( \pm 43 \%)\end{array}$ & - \\
\hline $\begin{array}{c}\text { Z_3 } \\
{[\mathrm{w} / \mathrm{c}=0.45, \text { CEM III] }}\end{array}$ & $\begin{array}{c}1.0 \\
( \pm 6 \%)\end{array}$ & $\begin{array}{c}2.4 \\
( \pm 15 \%)\end{array}$ & $\begin{array}{c}2.2 \\
( \pm 14 \%)\end{array}$ & $\begin{array}{c}2.3 \\
( \pm 4 \%)\end{array}$ & $\begin{array}{c}454.6 \\
( \pm 141 \%)\end{array}$ & $\begin{array}{c}3308.0 \\
( \pm 153 \%)\end{array}$ \\
\hline $\begin{array}{c}\mathrm{Z}_{-} 4 \\
{[\mathrm{w} / \mathrm{c}=0.40, \text { CEM III] }}\end{array}$ & $\begin{array}{c}0.8 \\
( \pm 8 \%)\end{array}$ & $\begin{array}{c}0.7 \\
( \pm 28 \%)\end{array}$ & $\begin{array}{c}0.7 \\
( \pm 24 \%)\end{array}$ & $\begin{array}{c}1.7 \\
( \pm 70 \%)\end{array}$ & $\begin{array}{c}1.5 \\
( \pm 38 \%)\end{array}$ & $\begin{array}{c}5.0 \\
( \pm 42 \%)\end{array}$ \\
\hline
\end{tabular}

The values of water absorption coefficient for the tested mortars after a given number of freeze-thaw cycles $n$, is presented in Figure 3. For samples with the lower $\mathrm{w} / \mathrm{c}=0.40$ made with CEM III, after first $150 \mathrm{f}$-t cycles, one can observe that transport properties does not change significantly. Both gas permeability and water absorption coefficient, remain constant. The cement mortar specimens with the highest value of gas permeability (samples of series Z_3 after 75 and 100 freeze and thaw cycles) have the highest rate of water absorption. It implies that the microcracks and capillary pores are saturated in a short time. Furthermore, after $24 \mathrm{~h}$, it is noticed that the top of the samples becomes wet. The narrow channels between the larger pores are broken, which is manifested by faster water uptake. Comparing the obtained experimental data, one can observe that the change of transport properties is correlated with the change of pore size distribution. In particular, it is associated with increase volume of pores with diameters larger than $100 \mathrm{~nm}$, notably the second peak in differential pore size distribution, see Fig. 2. Micro-cracking, induced by frost action, tends to connect the capillary pores. The results emphasize that the 
microcracks have a significant influence on permeability. Meanwhile, the water absorption is less sensitive to microcracks.

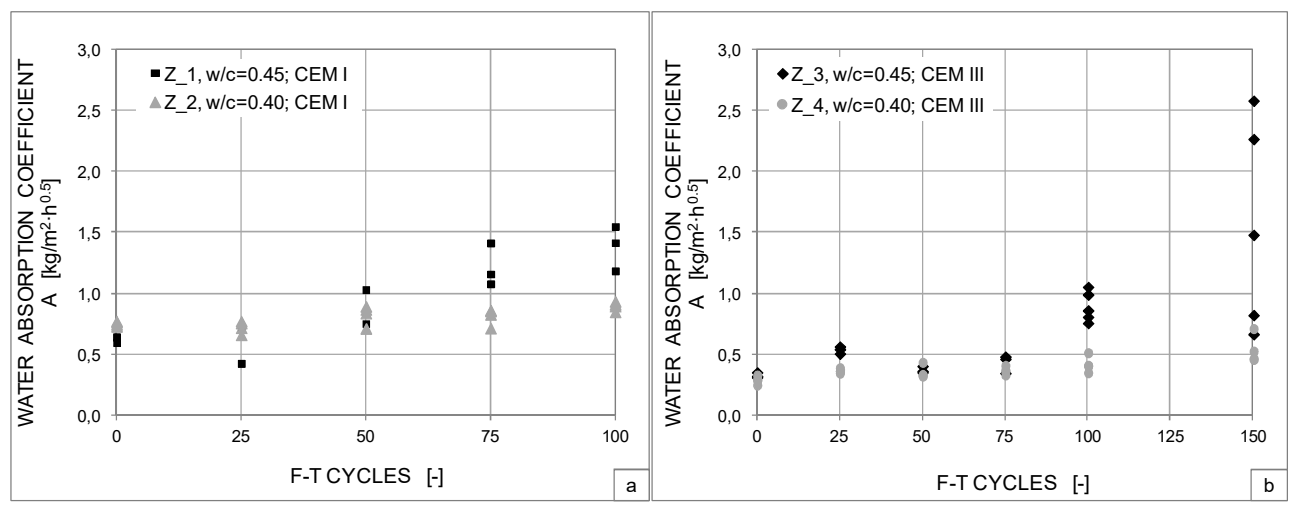

Fig. 3. Evolution of cement mortars water absorption coefficient with the rising number of f-t cycles for: (a) Z_1 and Z_2 and (b) Z_3 and Z_4.

\section{Conclusions}

The performed tests enable the analysis of transport properties of cement mortars subjected to cyclic water freezing. Damage as a consequence of the progressive deterioration of the microstructure of material, is associated with the physical degradation process caused by frost action. On the basis of tests results, following conclusions can be drawn:

- the transport properties are related to the pore size distribution and interconnectivity of the pore system of cement mortars. The gas permeability of damaged mortar changes very significantly, an increase with several orders of magnitude can be noticed;

- the differences between total porosities of cement mortar samples after freeze-thaw cycles is rather small, when compared with the reference samples. However, it is evident that frost damage caused a redistribution of pore sizes for cement mortar: $Z_{-} 1$ and $Z_{-} 2$ after $50 \mathrm{f}-\mathrm{t}$ cycles and for $Z \_3$ after 100 cycles;

- the microcracks have a more significant influence on permeability and lesser influence on water absorption coefficient. Due to high connectivity and low tortuosity of cracking caused by water freezing, the pressure-induced gas flow through the cracked mortar occurs preferentially through the microcracks. Capillary absorption is proportional to the total effective porosity, which is not changed with the increasing number of freeze-thaw cycles;

- type of cement (CEM I or CEM III) influences the frost resistance of cement mortar. Although, for $\mathrm{w} / \mathrm{c}=0.45$, the application of CEM III does not eliminate frost damaged, the ice-induced degradation of microstructure is consequently reduce until 75 freeze-thaw cycles. Moreover, the samples with lower $\mathrm{w} / \mathrm{c}$ ratio $(\mathrm{w} / \mathrm{c}=0.40, \mathrm{CEM}$ III), are more resistant to cyclic water freezing, no structure deterioration can be noticed until 150 frost cycle.

\section{References}

1. A.M. Neville, Properties of concrete, Polish Cement Association, Krakow (2012)

2. Z. Lafhaj, M. Goueygou, A. Djerbi, M. Kaczmarek, Correlation between porosity, permeability and ultrasonic parameters of mortar with variable water/cement ratio and water content, Cem. Concr. Res. 36, 625-633 (2006)

3. H. Hilsdorf, J. Kropp, Performance Criteria for Concrete Durability, Rilem Report 12, CRC Press (1995) 
4. EN 196-1:2016-07, Methods of testing cement - Part 1: Determination of strength

5. PN-B-06250:1988, Polish Standard: Normal Concrete (1988)

6. E. W. Washburn, Note on a method of determining the distribution of pore size in a porous material, Proc. Natl. Acad. Sci. USA 7, 115-116 (1921)

7. S. Diamond, Mercury porosimetry: An inappropriate method for the measurement of pore size distributions in cement-based materials, Cem. Conc. Res. 30, 1517-1525 (2000)

8. R. Kummar, B. Bhattacharjee, Study on some factors affecting the results in the use of MIP method in concrete research, Cem. Concr. Res. 33, 417-424 (2003)

9. RILEM Technical Recommendation 116-PCD.1999, Permeability of concrete as a criterion of its durability, Mater. Struct. 32, 174-179 (1999)

10. J. J. Kollek, The determination of permeability of concrete to oxygen by the Cembureau method - a recommendation. Mater. Struct. 22, 225-230 (1989)

11. L. J. Klinkenberg, The permeability of porous media to liquids and gasses, American Petroleum Institute, 200-213 (1941)

12. EN ISO 15148:2002. Hygrothermal performance of building materials and products Determination of water absorption coefficient by partial immersion

13. Z. Wang, Q. Zeng, Y. Wu, L. Wang, Y. Yao, K. Li. Relative humidity and deterioration of concrete under freeze-thaw load. Constr. Build. Mater. 62, 18-27 (2014)

14. G. Wardeh, M. A. S. Mohamed, E. Ghorbel, Analysis of concrete internal deterioration due to frost action, J. Build. Phys. 35, 54-82 (2010) 